\title{
Thermal Decomposition Kinetics of Ursodeoxycholic Acid Drug Crystal
}

\author{
S. Ramukutty, R. Jeyasudha, E. Ramachandran* \\ Department of Physics, Thiruvalluvar College, Papanasam, India \\ Email: *esakkiramachandran@yahoo.co.in
}

How to cite this paper: Ramukutty, S., Jeyasudha, R. and Ramachandran, E. (2017) Thermal Decomposition Kinetics of Ursodeoxycholic Acid Drug Crystal. Journal of Crystallization Process and Technology, 7, 85-90.

https://doi.org/10.4236/jcpt.2017.74006

Received: June 9, 2017

Accepted: September 27, 2017

Published: September 30, 2017

Copyright (c) 2017 by authors and Scientific Research Publishing Inc. This work is licensed under the Creative Commons Attribution International License (CC BY 4.0).

http://creativecommons.org/licenses/by/4.0/

\begin{abstract}
The crystallization of ursodeoxycholic acid drug crystals in gel by reduction of solubility method is the first of its kind to be reported in literature. Monoclinic crystalline form of the structure was confirmed using single crystal X-ray diffraction analysis. This report deals with the kinetic analysis made from the thermogravimetric analysis/differential thermal analysis (TGA/DTA) data using Coats-Redfern (CR) relation. Thermodynamic parameters were also determined. Arrhenius equation for ursodeoxycholic acid was derived as $\mathrm{k}=3.10 \times 10^{10}$ $e^{-172581 / R T} \mathrm{~mol}^{-1} \cdot \mathrm{s}^{-1}$.
\end{abstract}

\section{Keywords}

Thermal Analysis, Thermal Decomposition Kinetics, Ursodeoxycholic Acid

\section{Introduction}

Pharmaceutical problems like the purity level, qualitative and quantitative analysis of drug formulations and polymorphism are resolved using thermal analysis [1] [2]. Kinetic analysis is the subject of interest for many investigators involved in the thermal decomposition field. Solid state kinetics studies have increasing importance in thermal analysis and being helpful in the calculation of the parameters of Arrhenius equation and to determine the mechanism of decomposition reaction. The shelf life period of the drugs can also be estimated by the kinetic parameters.

Ursodeoxycholic acid $\left(\mathrm{C}_{24} \mathrm{H}_{40} \mathrm{O}_{4}\right)$ [3 $\alpha, 7 \beta$-dihydroxyl-5 $\beta$-cholan-24-oic acid], (Figure 1(a)) is used to treat cholestatic diseases such as primary biliary cirrhosis and primary sclerosing cholangitis non-surgically [3]. Many studies on ursodeoxycholic acid carried out were found to be on their pharmaceutical properties [3] [4] [5] [6]. Crystallization of many organic compounds and drugs and their thermal analyses were reported by the authors [7]-[12]. Detailed analysis of 


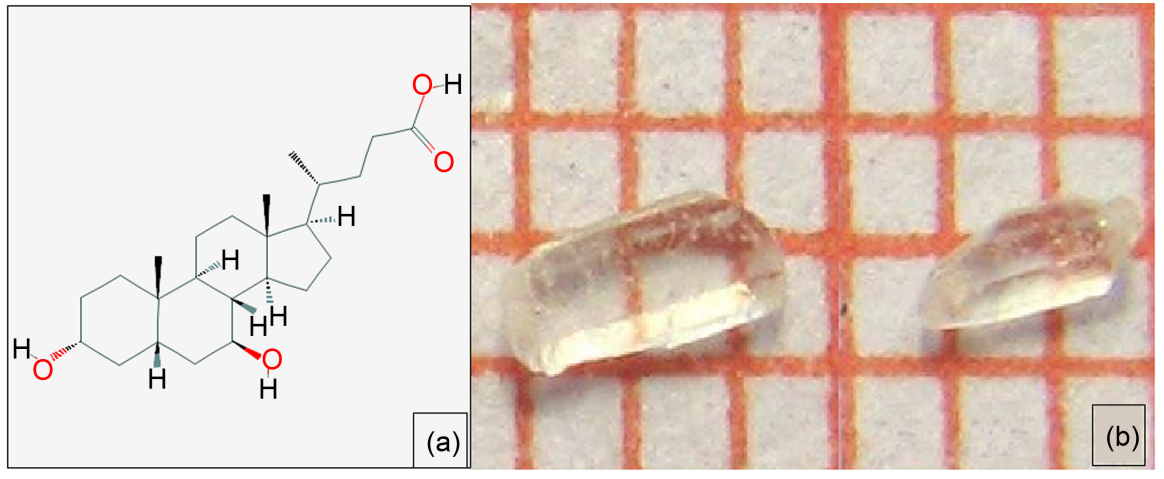

Figure 1. Ursodeoxycholic acid (a) molecular structure (b) crystal.

the thermal decomposition of ursodeoxycholic acid is scarce in literature and was undertaken.

Non-isothermal thermal analysis was carried out on the as grown single crystals of ursodeoxycholic acid crystallized from gel growth method. The grown crystal was subjected to single crystal X-ray diffraction analysis for the structure conformation. Coats-Redfern relation was applied on the thermal data to evaluate the kinetic parameters. Also the thermodynamic parameters were estimated. Arrhenius equation for ursodeoxycholic acid was determined.

\section{Experimental}

\subsection{Crystal Growth}

Commercial grade ursodeoxycholic acid drug was purchased from Lupin Pharmaceuticals Ltd., India. All other chemicals (AR grade) were purchased from s.d. chemicals Pvt. Ltd., India. Silica gel prepared from sodium metasilicate of specific gravity $1.06 \mathrm{~g} / \mathrm{cm}^{3}$ was used as crystal growth medium. Test tubes were used as crystal growth vessels. Crystal growth by single diffusion method was employed for the crystallization. The $\mathrm{pH}$ of the gel was set using acetic acid. $5 \% \mathrm{w} / \mathrm{v}$ of UDCA dissolved in methanol was placed over the set gel taken in the test tube. The experiment was carried out at room temperature $\left(\approx 27^{\circ} \mathrm{C}\right)$.

\subsection{Single Crystal X-Ray Diffraction Analysis (XRD)}

Enraf-Nonius CAD-4 Diffractometer, with $\operatorname{MoK} \alpha(\lambda=0.71073 \AA)$ radiation was used to obtain the accurate cell parameters of the grown UDCA single crystal at room temperature. Cell parameters were obtained from least-squares refinement of the setting angles of 346 reflections.

\subsection{Thermal Analysis}

Simultaneous thermogravimetric analysis (TGA) and differential thermal analysis (DTA) was carried out for the powdered sample of as grown crystals in the temperature range $40^{\circ} \mathrm{C}$ to $350^{\circ} \mathrm{C}$ under a constant heating rate of $10^{\circ} \mathrm{C} / \mathrm{min}$ using Perkin Elmer Diamond thermal analyzer. The crucible used was made of alumina which served as a reference for the sample. 


\section{Results and Discussion}

\subsection{Crystal Growth, XRD, TGA/DTA}

Transparent, rectangular platy crystals of size: $3.5 \times 1.5 \times 0.5 \mathrm{~mm}^{3}$ were crystallized in a week's time. The crystals were removed after a growth period of few weeks and photographed (Figure 1(b)).

The unit cell parameters were determined from the collected X-ray data. Lattice parameters of orthorhombic ursodeoxycholic acid form are: $a=26.56(15) \AA$, $b=13.25(5) \AA, c=12.31(4) \AA$, and the space group is $P 2_{1} 2_{1} 2_{1}$. These values agree well with the reported values in the literature [13].

TGA/DTA plot is presented in Figure 2. TGA/DTA of ursodeoxycholic acid showed no appreciable mass loss before the melting point $\left(200.6^{\circ} \mathrm{C}\right)$ which reasonably agrees with the literature value [14]. Absence of an endothermic peak around the boiling of point of water confirmed the anhydrate nature of the title compound. The DTA exhibits exothermic trend except two endothermic peaks $\left(200.6^{\circ} \mathrm{C}\right.$ and $\left.380^{\circ} \mathrm{C}\right)$. The thermal process around $200.6^{\circ} \mathrm{C}$ initiated the decomposition of the aliphatic chain into $\mathrm{CO}_{2}, \mathrm{C}_{2} \mathrm{H}_{4}$ and $\mathrm{CH}_{4}$ molecules and the mass loss at this stage supported this argument. Further the decomposition of the aromatic moieties happened above $380^{\circ} \mathrm{C}$ with the release of methane and water molecules.

\subsection{Kinetic Parameters}

The TGA data was analyzed using Origin Lab [15] and was fitted into the Coats

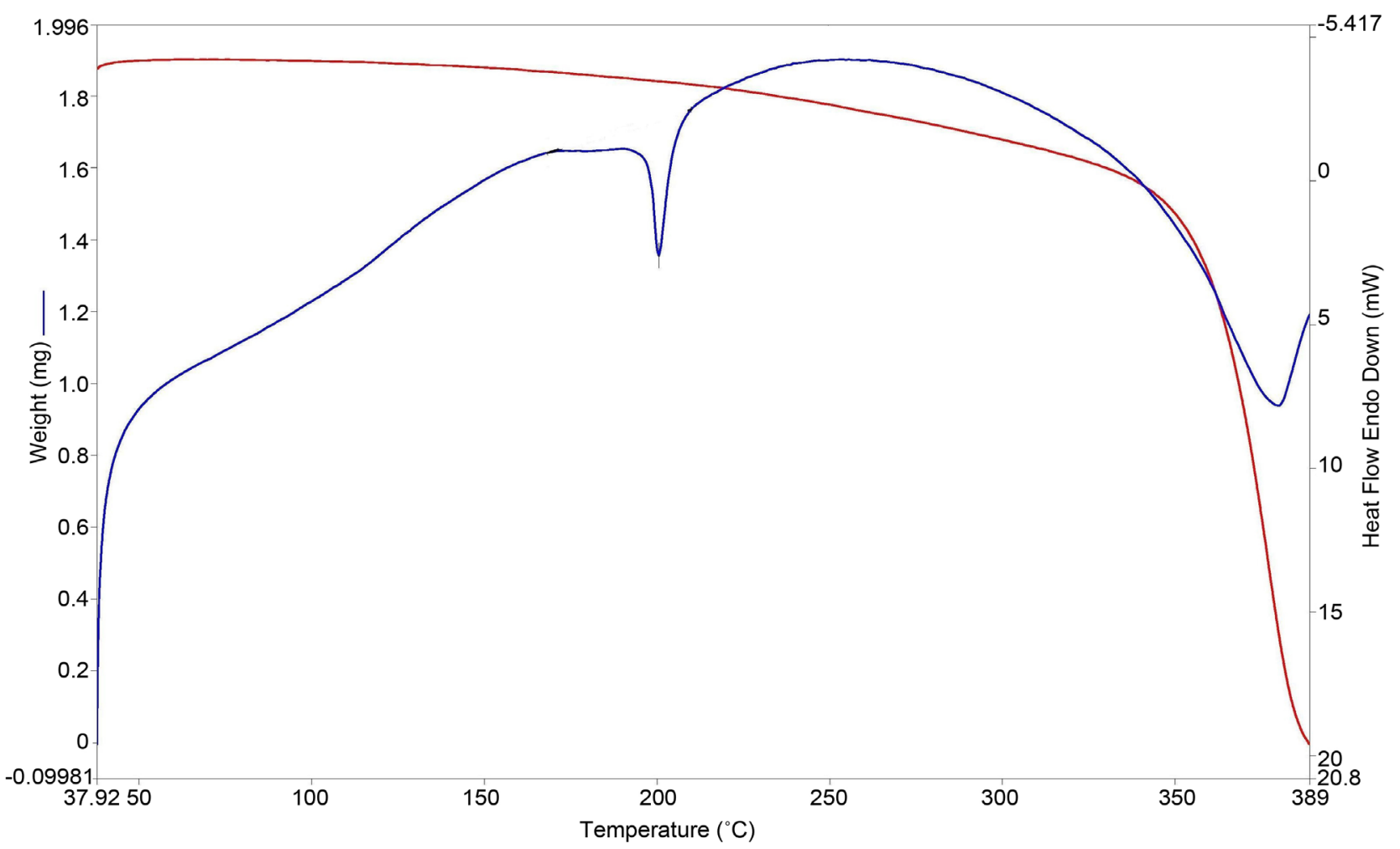

Figure 2. TGA/DTA of ursodeoxycholic acid. 
and Redfern relation [16] -Equation (1) to determine the values of activation energy $(E)$, frequency factor $(A)$ and order of the reaction $(n)$.

$$
\log \left[\frac{1-(1-\alpha)^{1-n}}{T^{2}(1-n)}\right]=\log \left[\frac{A R}{\beta E}\left(1-\frac{2 R \bar{T}}{E}\right)\right]-\left[\frac{E}{2.303 R T}\right]
$$

where, $\alpha$ is fraction of original substance decomposed at time $t$ and is calculated from TGA data using Equation (2),

$$
\alpha=\frac{m_{o}-m_{t}}{m_{o}-m_{f}}
$$

where $m_{t}$ is the mass at a given time, $m_{o}$ and $m_{f}$ are the initial and final masses of the sample respectively. $R$ denotes gas constant.

To determine the activation energy, frequency factor and order of reaction, the plot of $\log \left[\frac{1-(1-\alpha)^{1-n}}{T^{2}(1-n)}\right]$ versus $1 / T$ is drawn for different values of $n$ (Figure 3) and the best linear plot gives the correct value of $n$. This equation is valid for all values of $\mathrm{n}$ except $n=1$. The best linear plot is obtained for $n=0.25$. The activation energy and frequency factor are determined from the slope and intercept of the plot. The calculated values of activation energy and frequency factor are $172.581 \mathrm{~kJ} / \mathrm{mol}$ and $3.10 \times 10^{10} \mathrm{~s}^{-1}$ respectively. Using kinetic parameters, Arrhenius equation can be written ask $k=A \mathrm{e}^{-E / R T}$. The Arrhenius equation for is $k=3.10 \times 10^{10} e^{-172581 / R T} \mathrm{~mol}^{-1} \cdot \mathrm{s}^{-1}$.

\subsection{Thermodynamic Parameters}

The Thermodynamic parameters of ursodeoxycholic acid: entropy of activation

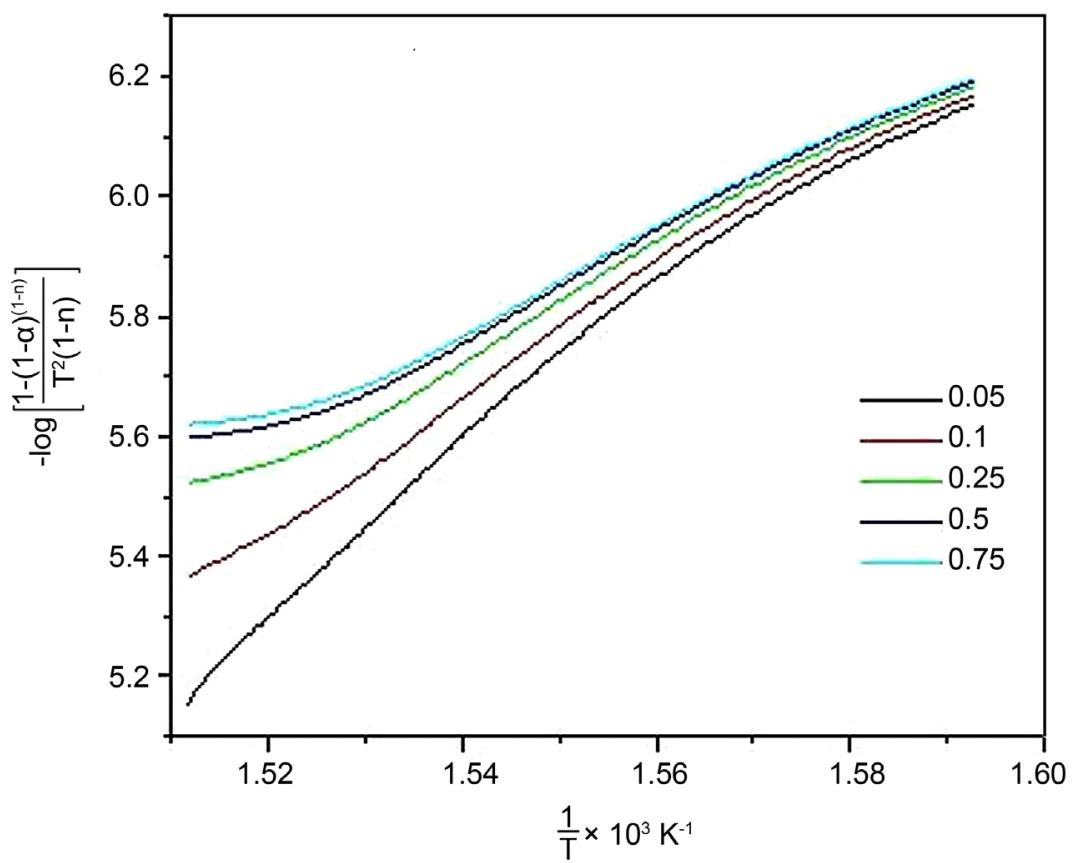

Figure 3. A plot of Coats-Redfern relation. 
$(\Delta S)$, enthalpy of activation $(\Delta H)$ and Gibbs free energy $(\Delta G)$ were calculated using Equations (3)-(5).

$$
A=(k T / h) e^{(\Delta S / R)}
$$

where $h$ and k are Planck's constant and Boltzmann constant respectively.

$$
\begin{gathered}
\Delta H=E-R T \\
\Delta G=\Delta H-T \Delta S
\end{gathered}
$$

The values of $\Delta S, \Delta H$ and $\Delta G$ are $-50.47 \mathrm{~J} / \mathrm{Kmol}, 167.22 \mathrm{~kJ} / \mathrm{mol}$ and 199.76 $\mathrm{kJ} / \mathrm{mol}$ respectively. Positive value of $\Delta G$ shows that the decomposition reaction of ursodeoxycholic acid is non-spontaneous.

\section{Conclusion}

Single crystals of ursodeoxycholic acid were crystallized by reduction of solubility method in gel for the first time. The crystal structure was confirmed using single crystal X-ray diffraction method. Non-isothermal thermal decomposition showed that the title compound is stable up to the temperature $200.6^{\circ} \mathrm{C}$, also the thermal data was analyzed using CR method and the order of reaction, activation energy and frequency factor were calculated. Arrhenius equation for ursodeoxycholic acid is $\mathrm{k}=3.10 \times 10^{10} e^{-172581 / R T} \mathrm{~mol}^{-1} \cdot \mathrm{s}^{-1}$. Thermodynamic parameter showed that the decomposition reaction of ursodeoxycholic acid is non-spontaneous.

\section{Acknowledgements}

The authors thank the University Grants Commission, Government of India, for providing Major Research Project Dr. K. Ravikumar and Dr. B. Sridhar, Laboratory of X-ray Crystallography, IICT, Hyderabad.

\section{References}

[1] Macedo, R.O., Aragao, C.F.S., do Nascimento, T.G. and Macedo, A.M.C. (1999) Application of Thermogravimerty in the Quality Control of Chloramphenicol Tablets. Journal of Thermal Analysis and Calorimetry, 56, 1323-1327. https://doi.org/10.1023/A:1010102422381

[2] Moura, E.A., Correia, L.P., Pinto, M.F., Procopio, V.V., De Sousa, F.S. and Macedo, R.O. (2010) Thermal Characterization of the Solid State and Raw Materials Flucaonazole by Thermal Analysis and Pyrolysis Coupled to GC/MS. Journal of Thermal Analysis and Calorimetry, 100, 289-293. https://doi.org/10.1007/s10973-009-0473-X

[3] Zein, C.O. (2010) Primary Biliary Cirrhosis, Primary Sclerosing Cholangitis, and Other Cholestatic Liver Diseases.

http://www.clevelandclinicmeded.com/medicalpubs/diseasemanagement/hepatolog $\mathrm{y} /$ cirrhosis-cholangitis-other-cholestatic-liver-disease/

[4] Sun, B., Hartl, F., Castiglione, K. and Weuster-Boltz, D. (2015) Dynamic Mechanistic Modeling of the Multienzymatic One-Pot Reduction of Dehydrocholic Acid to 12-Keto Ursodeoxycholic Acid with Competing Substrates and Cofactors. Biotechnology Progress, 31, 375-386. https://doi.org/10.1002/btpr.2036

[5] Guarino, M.P.L., Cocca, S., Altomare, A., Emerenziani, S. and Cicala, M. (2013) 
Ursodeoxycholic Acid Therapy in Gallbladder Disease, a Story Not Yet Completed. World Journal of Gastroenterology, 19, 5029-5034.

https://doi.org/10.3748/wjg.v19.i31.5029

[6] Angulo, P. (2002) Use of Ursodeoxycholic Acid in Patients with Liver Disease. Current Gastroenterology Reports, 4, 37-44.

https://doi.org/10.1007/s11894-002-0036-9

[7] Ramukutty, S. and Ramachandran, E. (2012) Mechanical and Thermal Studies on Gel Grown Racemic Ibuprofen Crystals. World Science and Technology, 2, 36-38.

[8] Ramukutty, S., Jeyasudha, R. and Ramachandran, E. (2013) Mechanical and Thermal Studies of Metronidazole Crystals. Indian Journal of Physics, 87, 1001-1004. https://doi.org/10.1007/s12648-013-0337-x

[9] Ramachandran, E. Ramukutty, S. and Jeyasudha, R. (2013) Thermal Kinetics of Gel Grown Diclofenac Drug Crystals. TEPE, 2, 44-46.

[10] Ramachandran, E. and Ramukutty, S. (2015) Kinetic Analysis on the Thermal Decomposition of Tinidazole Crystals. International Journal of Solid State Materials, 1 , $1-4$.

[11] Ramukutty, S. and Ramachandran, E. (2016) Mechanical Studies and Thermal Kinetics of Paracetamol Crystals. International Journal of Solid State Materials, 2, 46-50.

[12] Ramachandran, E. and Ramukutty, S. (2015) Mechanical Studies and Thermal Kinetics of Isoniazid Crystals. International Journal of Chemical Synthesis and Chemical Reactions, 1, 5-9.

[13] Higuchi. T., Kamitori, S., Hirotsu. K. and Takeda., H. (1985) Structure of Ursodeoxycholic Acid. Journal of the Pharmaceutical Society of Japan, 105, 1115-1121. https://doi.org/10.1248/yakushi1947.105.12_1115

[14] https://pubchem.ncbi.nlm.nih.gov/compound/ursodeoxycholic_acid\#section=Ch emical-and-Physical-Properties

[15] http://www.originlab.com/doc/Orglab/Orglab

[16] Coats, A.W. and Redfern, J.P. (1964) Kinetic Parameters from Thermogravimetric Data. Nature, 201, 68-69. https://doi.org/10.1038/201068a0 